\title{
One person with two DNA profiles: a(nother) case of mosaicism or chimerism
}

\author{
Vincent Castella $\cdot$ Maria del Mar Lesta • \\ Patrice Mangin
}

Received: 18 March 2008 / Accepted: 13 February 2009 /Published online: 25 February 2009

(C) Springer-Verlag 2009

\begin{abstract}
Nuclear DNA markers, such as short tandem repeats (STR), are widely used for crime investigation and paternity testing. STR were used to determine whether a piece of tissue regurgitated by a dog was part of the penis of a dead, emasculated, man. Unexpectedly, when analyzing the recovered material and a blood sample from the deceased, five out of the 18 loci differed. According to the results, one could have concluded that these samples originated from two different persons. However, taking into account contextual information and data from complementary genetic analyses, the most likely hypothesis was that the deceased was a genetic mosaic or a chimera. Within a forensic genetic context, such genetic peculiarities may prevent associating the perpetrator of an offense with a stain left at a crime scene or lead to false paternity exclusions. Fast recognition of mosaics or chimeras, adapted sampling scheme, as well as careful interpretation of the data should allow avoiding such pitfalls.
\end{abstract}

Keywords Short tandem repeat (STR) - Evidence evaluation · Mosaicism · Chimerism · Likelihood ratio approach

Electronic supplementary material The online version of this article (doi:10.1007/s00414-009-0331-1) contains supplementary material, which is available to authorized users.

V. Castella $(\bowtie) \cdot$ P. Mangin

Unité de Génétique Forensique, Centre Universitaire Romand

de Médecine Légale, rue du Bugnon 21,

1011 Lausanne, Switzerland

e-mail: Vincent.Castella@chuv.ch

M. Lesta $\cdot$ P. Mangin

Unité de Médecine Forensique,

Centre Universitaire Romand de Médecine Légale,

rue du Bugnon 21,

1011 Lausanne, Switzerland

\section{Introduction}

Nuclear DNA markers, such as short tandem repeats (STR), are widely used for crime investigation and paternity testing. They may lead to erroneous conclusions when the person at the source of the biological material analyzed is a genetic mosaic or a chimera.

Mosaicism refers to individuals with genetically distinct cell lines that originated from a single zygote, whereas chimerism refers to those who originated from more than one zygote [1]. Although these definitions are unambiguous, it may be difficult to determine, in routine cases, whether the coexistence of several STR profiles with an individual is a consequence of chimerism or mosaicism. Here, we report a case where a deceased man had two different tissue-specific STR profiles. Potential implications of such genetic particularities are discussed in a wider genetic forensic context.

\section{Case report}

An 88-year-old man was found dead at his home with a genital wound and part of his penis missing. No other injuries were observed on the body and no traces of violence were found nearby. The dog of the deceased, which was present at the scene, was suspected of being responsible for this partial emasculation. Following the administration of an emetic, a piece of connective tissue, about the size of a hazelnut, was recovered from its gastric content. It was assumed to be a fragment of the glans penis. Forensic genetic analyses were undertaken to investigate whether this piece of tissue effectively originated from the dead man. 


\section{Methods}

Peripheral blood from the deceased was analyzed to obtain a reference DNA profile for comparison with the glans penis DNA profile. DNA was extracted from $200 \mu$ of blood and about $100 \mathrm{mg}$ of tissue with the QIAamp DNA mini kit following the manufacturer's (Qiagen AG, Basel, Switzerland) instructions. DNA extracts were concentrated with Microcon 30 filters (Millipore AG, Volketswil, Switzerland) in order to get about $25 \mu \mathrm{l}$ final volume. DNA was amplified with the PowerPlex16 (Promega AG, Dübendorf, Switzerland) and AmpFlSTR SEFiler (Applera Europe, Rotkreuz, Switzerland) which allow to amplify a total of 18 STR markers (D3S1358, TH01, D21S11, D18S51, Penta E, D5S818, D13S317, D7S820, D16S539, CSF1PO, Penta D, VWA, D8S1179, TPOX, FGA, D2S1338, D19S433, and SE33 also called ACTBP2) using standard protocols. Polymerase chain reaction (PCR) products were analyzed on an ABI Prism 3100 genetic analyzer with Genemapper software (Applera Europe) following standard procedures.

\section{Results}

Unexpectedly, two STR profiles differing at five out of 18 loci $(28 \%)$ were obtained from the blood of the deceased and the piece of tissue regurgitated by the dog. When compared to the glans penis STR profile, the blood STR profile showed losses of heterozygosity at loci D3S1358, D5S818, and CSF1PO and allele changes at locus SE33 and FGA (Table 1). These particularities can be viewed in the figure available as ESM 1. New samples were collected from different tissues of the deceased in order to test if the deceased could be a genetic mosaic or a chimera. They were characterized either by single STR profiles identical to the one of the glans penis or with mixed STR profiles that corresponded to the addition of the glans penis and the blood STR profiles (Table 1). Single STR profiles identical to the one found in blood were not detected in other tissues.

\section{Discussion}

The results showed that the deceased had two genetically distinct cell lines. His physician was contacted and informed us that his patient suffered from a lymphoma but had not received blood transfusions or a bone marrow transplant. Although blood transfusion is not thought to affect DNA profiling [2], this medical information allowed to exclude chimerism associated with medical intervention (i.e., artificial chimerism) see, e.g., [3-6] as being the explanation of the observed pattern. Natural chimerisms resulting from the fusion of zygotes [7], from exchanges of blood between fetuses in utero, e.g., [8-10], or from double parental contribution, e.g., [11-14] as well as mosaicism are compatible with our data. Mosaics originate from somatic mutation and have generally only one STR locus altered $[15,16]$, but cancer may considerably increase the mutability of genetic markers, e.g., [17-21]. For instance, STR markers were altered respectively in $33 \%$ and $68 \%$ of oral and gastrointestinal cancer patients, with more than half of the patients having several loci altered $[18,21]$. STR loci from cancerous cells can be characterized by both partial (allele imbalance) and complete loss of heterozygosity $(\mathrm{LOH})$ and microsatellite instability (MIS, i.e., gain or loss of repetitive units), e.g., [17, 18, 21]. $\mathrm{LOH}$ is probably associated with chromosome instability and occurs randomly across the different STR loci. MIS is caused by slippage of the DNA polymerase during replication associated with mismatch repair, e.g., [21, 22] and, therefore, should preferentially affect loci having the highest germline mutation rate. This mechanism is compatible with our data since MIS-affected loci SE33 (also called ACTBP2) and FGA that have high germline mutation rates, whereas $\mathrm{LOH}$ was found in loci D3S1358, D5S818, and CSF1PO characterized with intermediate to low germline mutation rates (Table 1). Genotyping of the deceased man's parents is not possible in our case but could have allowed identifying that he was a

Table 1 Allele differences observed among DNA profiles from different tissues of the same dead person

\begin{tabular}{|c|c|c|c|c|c|}
\hline Sample origin & D3S1358 & D5S818 & CSF1PO & FGA & SE33/ACTBP2 \\
\hline $\begin{array}{l}\text { Penis glans, buccal cells (swab), back head skin, right leg skin, } \\
\text { right shoulder skin, liver, brain, and right leg muscle (a) }\end{array}$ & $15-18$ & $9-11$ & $10-12$ & $20-24$ & $14-29.2$ \\
\hline Blood (b) & $15-15$ & $11-11$ & $10-10$ & $21-24$ & $14-28.2$ \\
\hline Pubis skin, left leg muscle, spleen, left femur marrow, and sternum marrow (c) & $15-18$ & $9-11$ & $10-12$ & $20-21-24$ & $14-28.2-29.2$ \\
\hline Germline mutation rates $^{\mathrm{a}}$ & $0.12 \%$ & $0.11 \%$ & $0.16 \%$ & $0.28 \%$ & $0.64 \%$ \\
\hline Chromosomal location $^{\mathrm{a}}$ & $3 \mathrm{p} 21.31$ & $5 \mathrm{q} 23.2$ & $5 q 33.1$ & $4 q 28$ & $6 q 14$ \\
\hline
\end{tabular}

Profiles (c) displayed mixture characteristics and corresponded to the addition of profiles (a) and (b). No differences were observed among the 13 other STR loci tested (PowerPlex 16 and AmpFISTR SEfiler kits)

${ }^{a}$ from www.cstl.nist.gov/biotech/strbase/ 
chimera (all his alleles should be present in his parents) or a mosaic (some alleles were not inherited from his parents but created by mutations).

The frequency of occurrence of chimeras and mosaics in the general population is unknown. For the year 2006, hematopoietic stem cell allotransplants that result in artificial chimeras, concerned about 2/100,000 persons in France (www.agence-biomedecine.fr) as well as in Switzerland (www.bag.admin.ch/transplantation). Natural chimerism has certainly increased due to the implantation of several embryos following in vitro fertilization [23] and may concern up to $10 \%$ of the population [8]. Concerning mosaics, data from the Swiss Association of Cancer Registries (www.arst.ch), standardized for the European population age structure, allow an estimate of annual incidences of $24 / 100,000$ for oral cavity and pharyngeal cancers and of 52/100,000 for Hodgkin's disease, non-Hodgkins lymphoma, and leukemia. These cancers may interfere with forensic genetic applications since, for instance, the altered DNA from a buccal swab or from the blood of such mosaic will not match the DNA he transmitted to his offspring or the semen or epithelial cells left at the crime scene. Even if these phenomena are seldom, one could expect to find out several chimeras and mosaics within huge databases that can contain up to several millions of DNA profiles for crime investigation.

Following cautions should allow the minimization of the negative outcomes of genetic chimeras and mosaics. Before biological material is collected for crime investigation or paternity testing, it is highly recommended to ask whether the concerned person has received a transplant, has cancer, or has any known genetic particularity. These simple questions may allow focusing on tissues where the "original" STR profile of the person is likely to be found. When comparing STR profiles, partial match with apparent exclusions at a few loci might concern not only closely related persons but also a single genetic mosaic or chimera. Medical and/or familial information should allow the evaluation of these scenarios. Finally, when a known person is supposed to be a mosaic or a chimera, the STR profile should be established from several different tissues. In particular, it could be crucial for crime cases to compare DNA from the same tissue, e.g., a bloodstain vs. blood of the suspect or a semen stain vs. semen of the suspect. Alternatively, parents of chimeras and mosaics can be genotyped in order to identify their "original" alleles.

When reporting DNA results in a case, the weight of DNA evidence is generally evaluated with a likelihood ratio (LR) [24] which is an estimate of the probability of the DNA match under two alternative hypotheses that are generally $\mathrm{H} 1$ : the DNA came from the suspect (or the tested man is the father of the child) and H2: the DNA came from a random person (or a random man is the father of the child). LRs $>1$ support H1, LRs $=1$ are neutral, whereas LRs $<1$ support the alternative H2. Very high LRs, of the order of $10^{15}$ for 10 STR loci profile matches, can be obtained when using STR markers multiplexes. Such huge figures are difficult to justify and are somewhat biased towards H1. Consequently, some authors recommended reporting maximal LRs of $10^{9}$ in such situation [25]. In contrast, no threshold exists when genetic incompatibilities are observed. In such cases, LR values of zero are sometimes given, without any calculation. This can be the case for paternity tests when more than three exclusions are found, e.g., [26, 27]. This way of reporting the DNA evidence is biased toward $\mathrm{H} 2$ and would leave no chance for $\mathrm{H} 1$ to be true. It may result in false conclusions when a genetic mosaic or a chimera is involved in a case. It is, therefore, recommended that an appropriate probabilistic analysis of the crime or paternity case, taking into account inconsistencies between STR profiles, should be used [28].

Acknowledgments The authors wish to thank the staff of the laboratory for their work as well as T. Hicks and reviewers for their comments on earlier versions of the manuscript.

\section{References}

1. Milde A, Kühl-Burmeister R, Ritz-Timme S, Kaatsch H-J (1999) DNA typing in cases of blood chimerism. Int $\mathrm{J}$ Legal Med 112:333-335

2. Graham EAM, Tsokos M, Rutty GN (2007) Can post-mortem blood be used for DNA profiling after peri-mortem blood transfusion? Int J Legal Med 121:18-23

3. Dauber EM, Dorner G, Mitterbauer M et al (2004) Discrepant results of samples taken from different tissues of single individual. International Congress Series 1261. Elsevier, Amsterdam, pp 48-49

4. Pope S, Chapman H, Lambert JA (2006) Effect of bone marrow transplant on DNA profiles: a case example. Sci Justice 46:231-237

5. Dauber EM, Müller CJ, Schöniger-Hekele M et al (2006) Artificial blood chimerism and graft-versus-host disease after liver transplantation. International Congress Series 1288. Elsevier, Amsterdam, pp 840-842

6. Tran SD, Pillemer SR, Dutra A et al (2003) Differentiation of human bone marrow-derived cells into buccal epithelial cells in vivo: a molecular analytical study. Lancet 361:1084-1088

7. Yu N, Kruskall MS, Yunis JJ et al (2002) Disputed maternity leading to identification of tetragametic chimerism. N Engl J Med 346:1545-1552

8. Boklage CE (2006) Embryogenesis of chimeras, twins and anterior midline asymmetries. Hum Reprod 21:579-591

9. Rubocki RJ, McCue BJ, Duffy KJ, Shepard KL, Shepherd SJ, Wisecarver JL (2001) Natural DNA mixtures generated in fraternal twins in utero. J Forensic Sci 46:120-125

10. Gunzer C, Dauber EM, Petrasek M, Glock B, Schwartz DWM, Mayr WR (2004) Apparent exclusion of maternity in a twin chimera carrying only her twin brother's blood cells. Vox Sang 87:130 
11. Rodriguez Cardozo MB, Cólica MV, Abovich MA, Szöcs A, Di Lonardo AM (2004) Maternity testing in a chimerical child. International Congress Series 1261. Elsevier, Amsterdam, pp 502-504

12. Malan V, Gesny R, Morichon-Delvallez N et al (2007) Prenatal diagnosis and normal outcome of a $46, \mathrm{XX} / 46, \mathrm{XY}$ chimera: a case report. Hum Reprod 22:1037-1041

13. Wegener R, Weirich V, Dauber EM, Mayr WR (2006) Motherchild exclsuion due to peternal uniparental disomy 6 . Int J Legal Med 120:282-285

14. Verdiani S, Bonsignore A, Casarino L, Zia SC, Ferrari GM, De Stefano F (2009) An unusual observation of tetragametic chimerism. Forensic considerations. Int J Legal Med, in press

15. Rolf B, Wiegand P, Brinkmann B (2002) Somatic mutations at STR loci-a reason for three-allele pattern and mosaicism. Forensic Sci Int 126:200-202

16. Clayton TM, Guest JL, Urquhart AJ, Gill PD (2004) A genetic basis for anomalous band patterns encountered during DNA STR profiling. J Forensic Sci 49:1207-1214

17. Poetsch M, Petersmann A, Woenckhaus C, Protzel C, Dittberner T, Lignitz E, Kleist B (2004) Evaluation of allelic alterations in short tandem repeats in different kinds of solid tumors - possible pitfalls in forensic casework. Forensic Sci Int 145:1-6

18. Pai CY, Hsieh LL, Tsai CW, Chiou FS, Yang CH, Hsu BD (2002) Allelic alteration at the STR markers in the buccal tissue cells of oral cancer patients and the oral epithelial cells of healthy betel quid-chewers: an evaluation of forensic applicability. Forensic Sci Int 129:158-167

19. Peloso G, Grignani P, Rosso R, Previderè C (2003) Forensic evaluation of tetranucleotide STR instability in lung cancer.
International Congress Series 1239. Elsevier, Amsterdam, pp 719-721

20. Edelmann J, Lessig R, Hering S, Horn L-C (2004) Loss of heterozygosity and microsatellite instability of forensically used STR markers in human cervical carcinoma. International Congress Series 1261. Elsevier, Amsterdam, pp 499-501

21. Vauhkonen H, Hedman M, Vauhkonen M, Kataja M, Sipponen P, Sajantila A (2004) Evaluation of gastrointestinal cancer tissues as a source of genetic information for forensic investigations by using STRs. Forensic Sci Int 139:159-167

22. Parsons R, Li GM, Longley MJ et al (1993) Hypermutability and mismatch repair deficiency in $\mathrm{RER}^{+}$tumor cells. Cell 75:12271236

23. Malan V, Vekemans M, Turleau C (2006) Chimera and other fertilization errors. Clin Genet 70:363-373

24. Aitken CGG, Taroni F (2004) Statistics and the evaluation of evidence for forensic scientists. Wiley, Chichester

25. Foreman LA, Evett IW (2001) Statistical analyses to support forensic interpretation for a new ten-locus STR profiling system. Int J Legal Med 114:147-155

26. Adamek H, Baur M, Brinkmann B, Eisenmenger W (2002) Richtlinien für die Erstattung von Abstammungsgutachten. Dtsch Ärztebl 99:541-543

27. Cifuentes LO, Martínez EH, Acuña MP, Jonquera HG (2006) Probability of exclusion in paternity testing: time to reassess. J Forensic Sci 51:349-350

28. Dawid AP, Mortera J, Vicard P (2007) Object-oriented Bayesian networks for complex forensic DNA profiling problems. Forensic Sci Int 169:195-205 